\title{
Ketogenic Diet as Medical Nutrition Therapy
}

\author{
Dharini Krishnan ${ }^{1}$ Chetan Mehndiratta ${ }^{2}$ Tanmay Agrawal2t \\ ${ }^{1}$ Consultant Dietitian, Wellnesss Clinic, Chennai, India \\ 2 Medical Affairs, Signutra, New Delhi, India

\begin{abstract}
Address for correspondence Chetan Mehndiratta, MD, Medical Affairs, Signutra, Nehru Place, New Delhi, 110019, India (e-mail: chetan.mehndiratta@signutra.com).
\end{abstract}

\begin{abstract}
Keywords

- diabetes

- ketosis

- medical nutrition therapy

- ketogenic diet

- metabolic health

- obesity

Medical nutrition therapy is a therapeutic approach to treat medical conditions and their associated symptoms via using a specifically tailored diet devised under the supervision of a doctor and a registered dietitian or nutrition professional. Ketogenic diet primarily consists of the high amount of fats, a moderate amount of proteins, and very low carbohydrates. It is known to stimulate the metabolic effects of starvation by forcing the body to use primarily fat as a fuel source. Ketogenic diet was developed in the 1920s. Nowadays, it is gaining considerable attention as a potential weight-loss strategy because of the low-carb diet. However, it is being considered for use in several diseases/disorders also because of the beneficial effects on the metabolic health and nervous system. This review revisits the therapeutic potential of ketogenic diets in many pathological conditions and its role as a medical nutrition therapy. It also talks about the ill effects that the keto diet can have in case of self-usage and monitoring.
\end{abstract}

\section{Introduction}

Ketogenic diet is rich in fats with low carbohydrate content, and an adequate amount of protein ( - Fig. 1). Reduction in carbohydrate content puts the body into a metabolic state called ketosis. During ketosis, the body's metabolism increases to burn fat into ketones in the liver, which can further supply energy to the brain. ${ }^{1}$

A ketogenic diet is referred as therapy, due to its therapeutic effects. Dr Russel Wilder formulated the original ketogenic therapy, in 1923 at Mayo Clinic for the treatment of epilepsy in response to the observation that fasting had antiseizure properties. ${ }^{2}$ During fasting, the body metabolizes fat stores via lipolysis followed by $\beta$-oxidation of fatty acids into acetoacetate, $\beta$-hydroxybutyrate, and acetone as energy sources. The ketogenic diet having high fats and low carbohydrates activates the metabolic effects of starvation by diverting the metabolism toward fat consumption, primarily as a fuel source. ${ }^{3}$

Keeping in view the ability of ketogenic diet in controlling epilepsy, it is now utilized to treat other neurodegenerative diseases and other diseases including cancer and obesity. The present review highlights its role as a medical nutrition therapy (MNT) in treating various disease conditions. Until now several variations in classic ketogenic diets are seen, through the variation in fat

received

June 29, 2019

accepted after revision

November 5, 2019 to protein and carbs ratio, also called the macronutrient ratio. The classic strict keto diet carries a 4:1 ratio having four parts of fat for every one part of protein and carb, where $90 \%$ of calories come from fat, while $6 \%$ come from protein and $4 \%$ come from carb.

\section{Ketogenic Diet as Medical Nutrition Therapy}

Though ketogenic diet was first applied to reduce the incidence of an epileptic seizure, however, with time, it is being utilized to treat various other diseases due to its beneficial effects on the metabolic health and nervous system. ${ }^{4}$ Due to its application in various diseases, it is considered as an MNT for epilepsy as well as other diseases.

The ketogenic diet encourages the elimination of refined and processed carbohydrates and can be beneficial for people who are overweight, diabetic, or looking to improve their metabolic health. ${ }^{5}$

There are two aspects of the ketogenic diet:

1. Known or "direct" properties (high ketone-body levels, high fat, and restriction of calories from carbohydrate).

2. Potential "indirect" effects (e.g., effects on neurotransmitters, ion channels, or mitochondrial biogenesis).

The possible role of ketogenic diet as MNT has been explored in various diseases, as given in - Table 1 . $^{6-9}$
(C)2019 Novo Nordisk Education Foundation
License terms

()(1) $\ominus \circledast$ 
Some of the areas where ketogenic diet has a proven role as MNT are being described:

1. Weight loss: Ketogenic diet plays an essential role in weight loss. It takes more work to turn fat into energy than to turn carbs into energy. Therefore, a ketogenic diet can help expedite weight loss. Moreover, ketogenic diet has an adequate amount of proteins that satiates the body. ${ }^{5}$
2. Acne: An unhealthy and high glucose containing diet is one of the causes of acne. Consumption of a diet rich in processed and refined carbohydrates can alter gut bacteria and may cause more dramatic blood sugar fluctuations, both of which can have an influence on skin health. Therefore, ketogenic diet that is low in carb content reduces acne. ${ }^{6}$

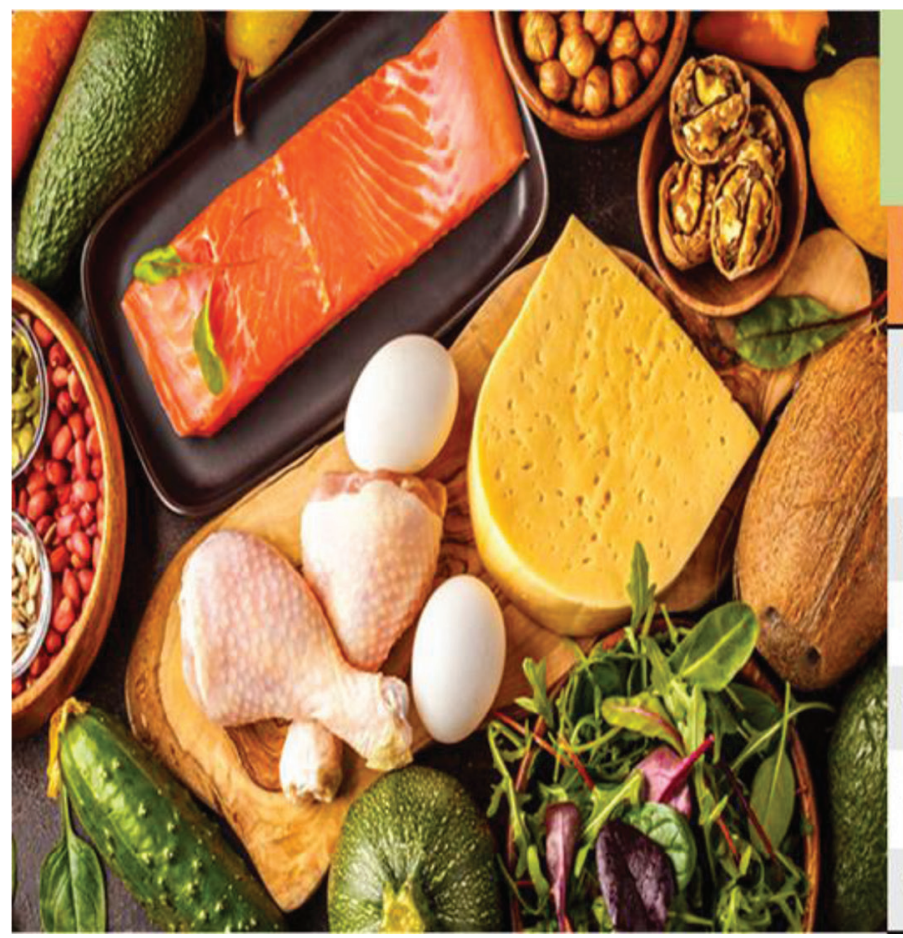

\begin{tabular}{|c|c|c|}
\hline $\begin{array}{l}\text { Fats } \\
(75 \%)\end{array}$ & $\begin{array}{l}\text { Carbohydrates } \\
(5 \%)\end{array}$ & $\begin{array}{l}\text { Proteins } \\
(20 \%)\end{array}$ \\
\hline Avocados & Asparagus & Salmon \\
\hline Yoghurt & Kale & Eggs \\
\hline Cheese & Lettuce & Bacon \\
\hline Butter & Cabbage & Turkey \\
\hline Olive oil & Broccoli & Sardines \\
\hline Hazelnuts & Cucumber & Shrimp \\
\hline Walnuts & Spinach & Duck \\
\hline
\end{tabular}

Fig. 1 The classic keto diet.

Table 1 Possible role of ketogenic diet as medical nutrition therapy in various diseases

\begin{tabular}{|l|l|l|}
\hline Name of the disease & $\begin{array}{l}\text { Duration of } \\
\text { ketogenic diet }\end{array}$ & Effects of ketogenic diet \\
\hline Epilepsy-seizures due to excessive brain activity & $\sim 3 \mathrm{mo}$ & $\begin{array}{l}\text { Reduces seizure frequency and severity in many children and } \\
\text { adults who don't respond well to drug therapy (classic ketogenic } \\
\text { diet) }\end{array}$ \\
\hline $\begin{array}{l}\text { Metabolic syndrome-prediabetes, insulin } \\
\text { resistance, high BP, large waistline, etc. }\end{array}$ & $\sim 12 \mathrm{wk}$ \\
\hline $\begin{array}{l}\text { Polycystic ovary syndrome-hormonal dysfunction in 14\% of body fat along with decreased triglycerides } \\
\text { resulting in irregular period and infertility } \\
\text { and blood sugar }\end{array}$ & $\sim 6 \mathrm{mo}$ reduce abdominal obesity, blood pressure \\
\hline $\begin{array}{l}\text { Diabetes-high blood glucose } \\
\text { autism-communication problem, social } \\
\text { interaction, repetitive behavior }\end{array}$ & $\sim 3 \mathrm{mo}$ & $\begin{array}{l}\text { Aeight loss averaged 12\%. Fasting insulin also declined by 54\% } \\
\text { normal HbA1c i.e., below 5.7\% }\end{array}$ \\
\hline $\begin{array}{l}\text { Obesity-disorder involving excessive body fat that } \\
\text { increases the risk of health problems }\end{array}$ & $\sim 4-24 \mathrm{wk}$ & $\begin{array}{l}\text { May experience improvements in behavior when ketogenic } \\
\text { diets are used in combination with other therapies }\end{array}$ \\
\hline $\begin{array}{l}\text { Amyotrophic lateral sclerosis-disease involving } \\
\text { neuronal death }\end{array}$ & $\begin{array}{l}\text { Very effective for weight loss in obese people due to its } \\
\text { powerful appetite-suppressing effects }\end{array}$ \\
\hline $\begin{array}{l}\text { Alzheimer's and Parkinson's disease-neuro } \\
\text { diseases }\end{array}$ & $\begin{array}{l}\text { The ability of ketone bodies to stimulate ATP synthesis as } \\
\text { well as to bypass inhibition of complex I in the mitochondrial } \\
\text { respiratory chain }\end{array}$ \\
\hline
\end{tabular}

Abbreviations: ATP, adenosine triphosphate; BP, blood pressure; HbA1c, hemoglobin A1c. 
3. Headache: In an open-label, single-arm, clinical study conducted in patients with drug-resistant chronic cluster care headache $(\mathrm{CCH})$ who underwent a 12-week ketogenic diet (modified Atkins diet), amelioration in clinical feature of $\mathrm{CCH}$ was observed. ${ }^{10}$

4. Cardiac health: When the ketogenic diet is followed in a healthy manner (which considers avocados a healthy fat instead of pork rinds), there is some evidence that the diet can improve heart health by reducing cholesterol (-Fig. 2). High-density lipoprotein (good) cholesterol levels significantly increase, while the low-density lipoprotein (bad) cholesterol decreases. ${ }^{11}$

5. Health of women with Polycystic ovarian syndrome: An endocrine disorder that causes enlarged ovaries with cyst is also negatively affected by a high-carbohydrate diet. ${ }^{12}$ A diet low in carbs, that is the ketogenic diet, helps in increased weight loss, hormonal balance, improved luteinizing hormone/follicle-stimulating hormone ratios, and improved fasting insulin.

6. Migraine: Ketogenic diet contributes to restore brain excitability and metabolism and to counteract neuroinflammation in migraine. In a study by Di Lorenzo et al, the group having ketogenic diet observed a reduction in the baseline attack frequency (2.9-0.71 attacks per month), number of days with headaches (5.11-0.91 days per month), and tablet intake (4.91-0.51 doses per month) $(p<0.0001$ for all). Efficacy of ketogenic diet could be related to its ability to enhance mitochondrial energy metabolism and counteract neural inflammation. ${ }^{13}$

7. Ketogenic diet and cancer: A ketogenic diet may help in treating some types of cancer when used along with traditional treatments such as chemotherapy and radiation therapy. Ketogenic diets have gained popularity among patients and researchers alike due to their putative antitumor mechanisms. The probability of achieving an antitumor effect seems greater than that of causing serious adverse effects, suggesting a high benefit-risk balance with ketogenic diet. Vander Heiden et al observed that tumors take up enormous amounts of glucose compared with the surrounding tissue and eventually produce lactate through the aerobic glycolytic pathway. Limitation of glucose availability in a cancer cell may reduce energy production in cancer cells, thereby decreasing tumor proliferation. ${ }^{14}$

Some of the preclinical studies have shown the effect of ketogenic diet to reduce tumor growth and improve survival in animal models of malignant glioma, prostate cancer, colon cancer, and gastrointestinal cancer. Low calorie diet,

\section{A HIGH FAT DIET REVERSES ALL CORONARY RISK FACTORS MORE EFFECTIVELY THAN A LOW FAT DIET}

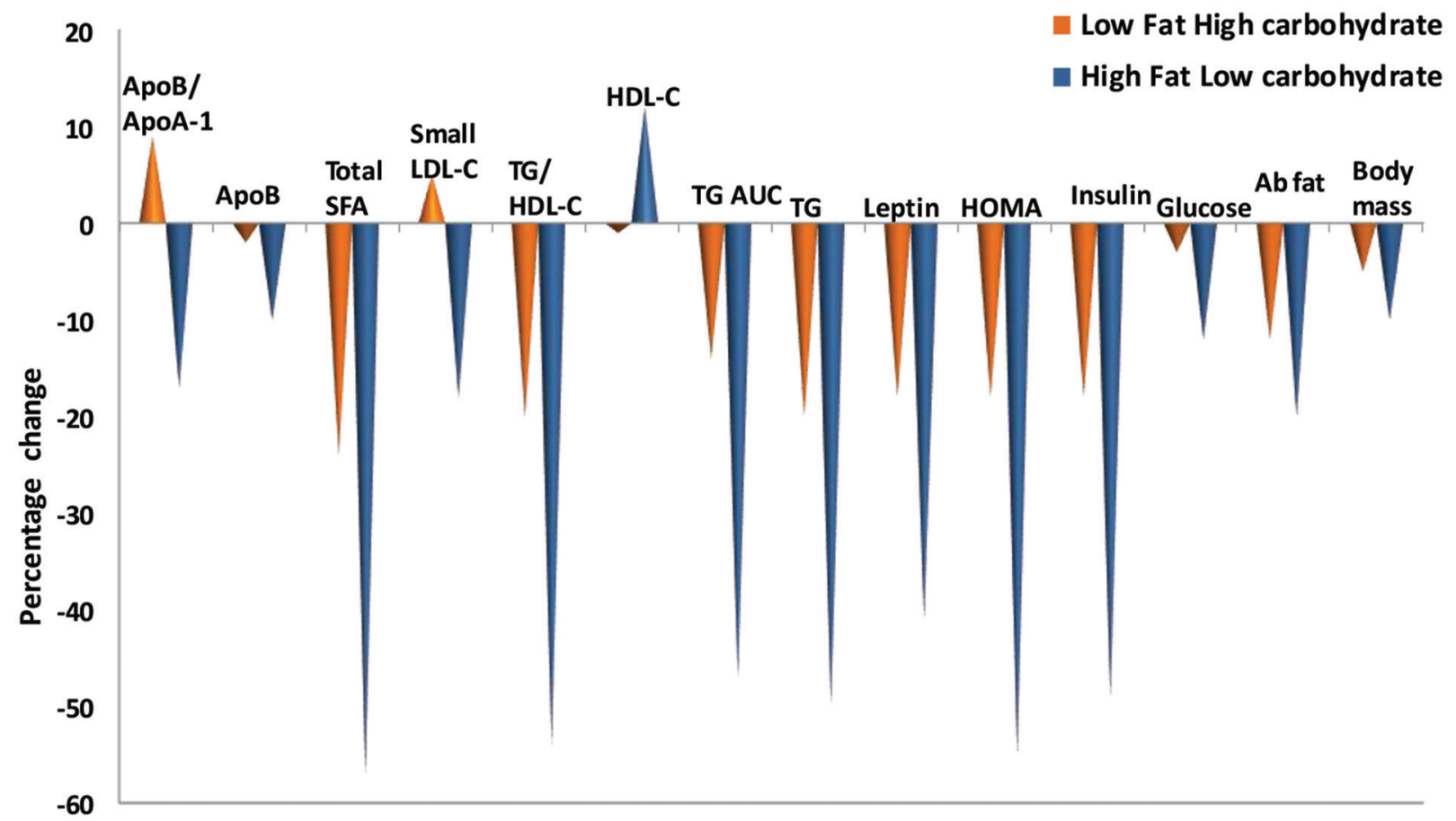

Jeff S. Volek, Maria Luz Fernandez, Richard D. Feinman, Stephen D. Phinney “Dietary carbohydrate restriction induces a unique metabolic state positively affecting atherogenic dyslipidemia, fatty acid partitioning, and metabolic syndrome" Progress in Lipid Research 47 (2008) 307-318

Fig. 2 Beneficial effect of high fat diet on lipid and insulin profile. AUC, area under (time) curve; HDL, high-density lipoprotein; LDL, lowdensity lipoprotein; TG, triglycerides. 
such as fasting inducing a state of ketosis, has been shown to enhance the responsiveness of cancer cells to chemotherapy in preclinical cancer therapy models and to ameliorate some of chemotherapy-induced adverse effects in normal tissues. Ketogenic diet has been studied intensively in European country including Germany. In these studies, the physical condition was successfully improved and tumor shrinkage was observed by ketogenic diet. ${ }^{15}$

\section{Possible Disadvantages}

Despite numerous advantages associated with the ketogenic diet, not all carbohydrates are considered equal. Many health benefits come from a diet that includes a variety of nutrient-dense, fibrous carbs, fruits, vegetables, lean proteins, and healthy fats. Once the body is in ketosis state, the body burns fat instead of glucose, which leads to keto flu. Symptoms of the keto flu can include everything from headache, weakness, and irritability, to constipation, nausea, and vomiting. ${ }^{16}$ So, one should never consider the ketogenic diet as a source of treatment for any disease or disorder on its own.

In certain people, ketogenic diet can be used only for short periods, as there are adverse effects associated with it including gastric issues. This could arise due to the high-fat content of the diet. The high protein can cause uric acid accumulation and create a condition like gout. It may be less suitable for elite athletes or those wishing to add large amounts of muscle or weight.

\section{Conclusion}

Keto diet is emerging as a potential MNT in numerous ailment conditions. However, it should be taken only in addition to standard therapies, under the supervision of a doctor and dietitian. As with any diet, it will only show its therapeutic benefits, if you are consistent with it for long-term intake. Overall, the ketogenic diet's potential to improve health is very promising.

\section{Note}

All named authors meet the International Committee of Medical Journal Editors (ICMJE) criteria for authorship for this manuscript, take responsibility for the integrity of the work, and have given final approval for the version to be published.

\section{Funding}

None.

\section{Conflict of interest}

None declared.

\section{References}

1 The Charlie Foundation. Available at: https://charliefoundation.org/diet-plans. Accessed March 6, 2019

2 Hippocrates on the Sacred Disease. Available online: http://classics.mit.edu/Hippocrates/sacred.html. Accessed May 16, 2017

3 McDonald TJW, Cervenka MC. The expanding role of ketogenic diets in adult neurological disorders. Brain Sci 2018;8(8):148

4 Ruskin DN, Masino SA. The nervous system and metabolic dysregulation: emerging evidence converges on ketogenic diet therapy. Front Neurosci 2012;6:33 10.3389/fnins.2012.00033

5 Pérez-Guisado J. [Ketogenic diets: additional benefits to the weight loss and unfounded secondary effects]. Arch Latinoam Nutr 2008;58(4):323-329

6 Paoli A, Rubini A, Volek JS, Grimaldi KA. Beyond weight loss: a review of the therapeutic uses of very-low-carbohydrate (ketogenic) diets. Eur J Clin Nutr 2013;67(8):789-796

7 Barañano KW, Hartman AL. The ketogenic diet: uses in epilepsy and other neurologic illnesses. Curr Treat Options Neurol 2008;10(6):410-419

8 Kashiwaya Y, Takeshima T, Mori N, Nakashima K, Clarke K, Veech RL. D- $\beta$-hydroxybutyrate protects neurons in models of Alzheimer's and Parkinson's disease. Proc Natl Acad Sci U S A 2000;97(10):5440-5444

9 Zhao Z, Lange DJ, Voustianiouk A, et al. A ketogenic diet as a potential novel therapeutic intervention in amyotrophic lateral sclerosis. BMC Neurosci 2006;7:29 10.1186/1471-2202-7-29

10 Di Lorenzo C, Coppola G, Di Lenola D, et al. Efficacy of modified Atkins ketogenic diet in chronic cluster headache: an open-label, single-arm, clinical trial. Front Neurol 2018;9:64 10.3389/fneur.2018.00064

11 Volek JS, Fernandez ML, Feinman RD, Phinney SD. Dietary carbohydrate restriction induces a unique metabolic state positively affecting atherogenic dyslipidemia, fatty acid partitioning, and metabolic syndrome. Prog Lipid Res 2008;47(5):307-318

12 Mavropoulos JC, Yancy WS, Hepburn J, Westman EC. The effects of a low-carbohydrate, ketogenic diet on the polycystic ovary syndrome: a pilot study. Nutr Metab (Lond) 2005;2:35 10.1186/1743-7075-2-35

13 Di Lorenzo C, Coppola G, Sirianni G, et al. Migraine improvement during short lasting ketogenesis: a proof-of-concept study. Eur J Neurol 2015;22(1):170-177

14 Vander Heiden MG, Locasale JW, Swanson KD, et al. Evidence for an alternative glycolytic pathway in rapidly proliferating cells. Science 2010;329(5998):1492-1499

15 Chung HY, Park YK. Rationale, feasibility and acceptability of ketogenic diet for cancer treatment. J Cancer Prev 2017;22(3):127-134

16 Here Are the Worst Side Effects of the Keto Diet. https://www. healthline.com/health-news/worst-side-effects-of-the-keto-diet. Accessed December 20, 2019 